Review

\title{
Ambient Assisted Living and Health-Related Outcomes-A Systematic Literature Review
}

\author{
Alexandra Queirós ${ }^{1,2, *}$, Ana Dias ${ }^{3}$ (D) Anabela G. Silva ${ }^{1,4}$ and Nelson Pacheco Rocha ${ }^{2,5}$ (D) \\ 1 Health Sciences School, University of Aveiro, 3810-193 Aveiro, Portugal; asilva@ua.pt \\ 2 Institute of Electronics and Telematics Engineering of Aveiro, University of Aveiro, 3810-193 Aveiro, \\ Portugal; npr@ua.pt \\ 3 Department of Economics, Management, Industrial Engineering and Tourism, GOVCOP, University of \\ Aveiro, 3810-193 Aveiro, Portugal; anadias@ua.pt \\ 4 CINTESIS-Center for Health Technology and Services Research, University of Aveiro, \\ 3810-193 Aveiro, Portugal \\ 5 Medical Sciences Department, University of Aveiro, 3810-193 Aveiro, Portugal \\ * Correspondence: alexandra@ua.pt; Tel.: +351-234-372-450
}

Academic Editors: Shuai Zhang, Chris Nugent, Jens Lundström and Min Sheng

Received: 30 May 2017; Accepted: 5 July 2017; Published: 10 July 2017

\begin{abstract}
The active ageing paradigm aims to contribute to the expectation of a long, autonomous, independent and healthy life. Ambient Assisted Living (AAL) promotes the development of technological solutions that might have a key role in not only the optimization of support services for older adults but also in the mitigation of their disabilities. This article presents a systematic literature review of how the impact of AAL technologies, products and services is being assessed in terms of its health-related outcomes. The main objective of this article is to contribute to the understanding of how state-of-the-art AAL solutions might influence the health conditions of older adults. The method used to conduct this systematic literature review followed the guidelines of the Preferred Reporting Items for Systematic Reviews and Meta-Analyses (PRISMA). The results show that the reviewed articles report not only the use of technological assessment instruments but also instruments to measure health-related outcomes such as quality of life.
\end{abstract}

Keywords: ambient assisted living; older adults; health-related outcomes; quality of life; systematic review

\section{Introduction}

Health and social care are facing extraordinary challenges due to the changing patterns of disease, the demanding expectations of patients, financial restrictions and an ever-increasing ageing population. It is estimated that the number of people aged 60 and over globally will increase from 900 million in 2015 to 1.4 billion by 2030 and 2.1 billion by 2050 [1].

The World Health Assembly of the World Health Organization (WHO) defined a strategy and an action plan on ageing and health for 2016-2020, considering the active ageing paradigm. For this strategy and action plan, the WHO envisages a world in which everyone can live a long, autonomous, independent and healthy life [2]. In this context, it is widely agreed upon that the adoption of technological solutions is fundamental not only to the optimization of support services but also for the mitigation of disabilities; particularly those resulting from the natural ageing process.

Ambient Assisted Living (AAL) is one of the resources available and refers to intelligent technologies, products and services embedded in the physical environment and aimed at the support of older adults, promoting their autonomy, independence, safety, social participation and well-being [3]. 
Health conditions are influenced by factors distributed across different levels of impact that interact with each other continuously and in subtle ways [4], namely physical (e.g., physical functions), mental (e.g., anxiety or depression), behavioral (e.g., medication adherence), social (e.g., activities and participation) and environmental (e.g., the support of relatives or access to health care and social services). For instance, the impact of a diet plan is influenced by an individual's health conditions as well as behavioral factors such as physical activity and environmental factors that either hinder or facilitate this physical activity.

Therefore, in addition to the measurement of clinical parameters, a broad range of other health-related outcomes linked to the major aspects of a person's life should be considered when measuring the experience of illness, such as their quality of life (i.e., personal well-being and satisfaction with life [5]). These measurements are complex, as they are inherently subjective (i.e., most of them are directly reported by patient-patient report outcomes [6]) and are focused on a person's daily life experiences; this means that technological solutions might have an important role in their optimization.

After years of research, innovation and development in the AAL field, there is still a lack of knowledge concerning the impact of the solutions being developed in terms of their health-related outcomes. This article presents a systematic literature review on how the impact of AAL technologies, products and services is being assessed in terms of health-related outcomes and its main objective is to contribute to the understanding of how assessment instruments to measure health-related outcomes are being used to evaluate state-of-the-art AAL solutions.

\section{Materials and Methods}

Considering the aforementioned objective, a systematic literature review was performed. This systematic review was informed by the following research questions:

- What AAL solutions reported in the literature to improve health conditions were evaluated in terms of health-related outcomes?

- Does the literature present evidence on the impact of AAL solutions in terms of health-related outcomes?

- What methods are being used to measure the impact of AAL solutions in terms of health-related outcomes?

To perform the systematic literature review, the authors defined a review protocol with explicit descriptions of the methods to be used and the steps to be taken. The protocol followed the guidelines of the Preferred Reporting Items for Systematic Reviews and Meta-Analyses (PRISMA) [7] and is briefly described in this section.

The resources chosen for the review were three general databases (Web of Science, Academic Search Complete and Science Direct) and two specific databases (PubMed, a medical-related database; and IEEE Explorer, a technological database). Two keywords were used without any language restriction: (i) 'Ambient Assisted Living', as this was the focus of this review; and (ii) 'Ambient Intelligence' (AmI), since AAL is one of its sub-areas.

The review was performed on 13 February 2017 and included all references published from 1 January 2007 (due to the fact that the European Union's Ambient Assisted Living Joint Programme was proposed in 2007 [8]) until 31 December 2016.

In terms of inclusion and exclusion criteria, articles were included if they reported AAL or AmI solutions that might influence the health conditions of older adults and if they explicitly referred to health-related outcomes. Articles were excluded if they were not written in English, if they did not have abstracts, if they were prefaces, or if they reported on reviews, surveys or market studies.

After the removal of duplicates and articles without abstracts, the selection of the remainder of the articles was performed by two authors in three steps: (i) first, the authors assessed all titles and abstracts for relevance and those clearly not meeting the eligibility criteria were removed; (ii) the 
authors then assessed the full text of the remaining articles against the outlined inclusion and exclusion criteria and the final list of the articles to be considered for the review was created.

Throughout this entire process, any disagreement between the authors was discussed and resolved by consensus.

Concerning data extraction, the following information was registered in a data sheet prepared by the authors for each of the articles included in the review: (i) the demographics of the published work (i.e., authors, year or source of publication); (ii) the scope of the article; (iii) details of the research method used; (iv) the technologies being reported upon; (v) the problems solved by these technologies; (vi) the health-related outcomes that were measured and the respective measurement instruments; and (vii) the evidence of the impact of the AAL solutions being reported.

Finally, the main objective of the analysis stage was to answer the research questions mentioned above. To accomplish this, the included articles were classified into one of the following classes: (i) technologies; (ii) systems; and (iii) conceptual articles. The operational definitions used in this review for each of these classes were [3]:

- Technologies: studies that describe the structure and rules needed to make judgments about AAL systems and how to implement them; the hardware components required for the implementation of AAL systems; the technologies and methods used to model the situation of a person, a place or object considered relevant to the interaction between a user and a system; technologies and methods that enhance the effectiveness and usability of a system and its interfaces; or studies related to privacy and security challenges imposed by AAL implementations.

- Systems: practical AAL systems applied in a specified context and with a well-defined aim.

- Conceptual articles: innovative concepts related to AAL or that may contribute to its development.

Furthermore, the full text of each retrieved article was analyzed in terms of the involvement of end users in the different development phases (e.g., functional requirements, validation or evaluation), as well as in terms of the importance of the health-related outcomes that were measured and the respective measurement instruments, in order to systematize the evidence on how the impact of AAL solutions on the health conditions of older adults is being assessed.

\section{Results}

Figure 1 presents the PRISMA flowchart of the systematic review reported in the present article. A total of 4787 articles was retrieved from the initial search of the selected databases. After applying the inclusion and exclusion criteria, 32 articles were selected. Table 1 presents the scope of the selected articles.

The full texts of the 32 retrieved articles were classified considering the three areas previously defined (i.e., technologies, systems, and conceptual articles). As a result, 15 articles were classified as reporting on technologies, 16 were classified as reporting on systems and one article was classified as a conceptual article (Table 2). 
Table 1. Scope of the selected articles.

\begin{tabular}{|c|c|c|}
\hline Ref. & Year & Objective \\
\hline [9] & 2016 & $\begin{array}{l}\text { Development of automated methods to infer behaviors such as anxiety, poor sleep, depression and loneliness in order to tailor assistive technology for the purpose of } \\
\text { providing just-in-time adaptive interventions targeting multiple domains. }\end{array}$ \\
\hline [10] & 2009 & Development of a medical teleconsulting application based on the IP Multimedia Subsystem (IMS). \\
\hline [11] & 2011 & Development and test of a real-time system based on a self-calibrated 3D time-of-flight camera to detect the falls of older adults. \\
\hline [12] & 2016 & Detection of a patient's emotional state by analyzing their physiological signals, facial expressions and behaviors. \\
\hline [13] & 2012 & $\begin{array}{l}\text { Application of the AAL paradigm to increase the quality of life of patients by developing novel devices and applications to enhance contact with their daily } \\
\text { environments. }\end{array}$ \\
\hline [14] & 2014 & $\begin{array}{l}\text { Designing, deploying and testing an integrated home-based AAL system for older adults, consisting of ambient monitoring, behavior recognition and feedback to } \\
\text { support self-management of wellness. }\end{array}$ \\
\hline [15] & 2008 & $\begin{array}{l}\text { Development of Geriatric Ambient Intelligence: an intelligent environment that integrates multi-agent systems, mobile devices, RFID, and Wi-Fi technologies to } \\
\text { facilitate the management and control of geriatric residences, allowing case-based planning, the scheduling of functionalities and the facilitation of patient data. }\end{array}$ \\
\hline [16] & 2009 & Development of a tool to evaluate the quality of life of older adults based on kitchen activity extracted from data provided by appliances. \\
\hline [17] & 2012 & Use of biofeedback systems to measure, quantify and improve the quality of sleep. \\
\hline [18] & 2016 & $\begin{array}{l}\text { Development of a cloud-based integrated approach that enables robotic devices to seamlessly deploy robotic applications, relieving the robots themselves from } \\
\text { computational burdens. }\end{array}$ \\
\hline [19] & 2011 & Design and evaluation of Aurama: a system to support the awareness of older adults living alone. \\
\hline [20] & 2010 & Overview of technical and other issues in extending at-home (@home) assistive technologies for older adults and disabled people. \\
\hline [21] & 2015 & $\begin{array}{l}\text { Presentation of a monitoring system, eWALL, that conforms Romanian healthcare regulations and the requirements of procedures for Chronic Obstructive Pulmonary } \\
\text { Disease and Mild Dementia patients. }\end{array}$ \\
\hline [22] & 2013 & Monitoring platform based on 3D sensors for AAL services delivered in smart environments. \\
\hline [23] & 2010 & Design approach, considering not only tasks but also the immediate emotions or habits and behaviors of users. \\
\hline [24] & 2009 & Products developed in the European MyHeart Project that intends to perform heart monitoring using wearable garments and portable devices. \\
\hline [25] & 2014 & Nighttime support of people in the early stages of dementia. \\
\hline [26] & 2015 & Development of a generic infrastructure that manages distributed applications for home care. \\
\hline [27] & 2016 & AmI testbed, investigating the performance of OLSR and WEP in indoor environments, considering a Line-of-Sight scenario. \\
\hline [28] & 2014 & Application of context awareness and artificial intelligence to provide digested and objective information about the evolution of a person's quality of life. \\
\hline [29] & 2010 & Combination of type-2 fuzzy sets and ontology models for diet assessment. \\
\hline [30] & 2013 & The living environment as a pseudo robot, providing a non-invasive, self-learning, intelligent control system that constantly adapts to the requirements of individuals. \\
\hline [31] & 2013 & Development of the Complete Ambient Assisted Living eXperiment (CAALYX) system. \\
\hline [32] & 2015 & A Multi-Agent System (MAS) specifically designed to manage data from Wireless Sensor Networks deployed in a residential home for older adults. \\
\hline [33] & 2014 & Analysis of the technology acceptance and the effects of AAL on the quality of life of people at an advanced age living in assisted-living homes. \\
\hline [34] & 2014 & Association between permanently deployed ambient sensors as part of smart aware apartments and clinically validated health-condition questionnaires. \\
\hline
\end{tabular}


Table 1. Cont.

\begin{tabular}{ccc}
\hline Ref. & Year & \multicolumn{1}{c}{ Objective } \\
\hline [35] & 2009 & $\begin{array}{l}\text { The Service-oriented programmable smart environments for older Europeans (SOPRANO) and its technical components as part of a socio-technical system that models } \\
\text { both the human and machine domains within a single conceptual framework. } \\
\text { Analysis of an intelligent built environment by undertaking a complex analysis of micro, meso and macro environment factors affecting an intelligent built } \\
\text { environment in order to present recommendations on how to increase efficiency and the ability to improve an inhabitant's quality of life. } \\
\text { Development of a technological platform to support innovative care provision allowing remote health and physical monitoring as well as cognitive and behavioral } \\
\text { assessment. }\end{array}$ \\
{$[36]$} & 2010 & $\begin{array}{l}\text { Development and demonstration of the general feasibility, scientific or technical effectiveness, social or legal plausibility, and the acceptability by end-users of } \\
\text { cooperating robots integrated with smart environments and acting in heterogeneous environments such as homes, condominiums and the outdoors. } \\
\text { Biofeedback system to prevent inactivity (often associated with blue moods and depression, atrophy and a rapid decrease of the plasticity of the brain and the aging of } \\
\text { neural cells). }\end{array}$ \\
{$[38]$} & 2012 & $\begin{array}{l}\text { Development of a mechatronic system to withdraw patients from their beds for bathing and basic healthcare as well as the development of a Medical Care Terminal } \\
\text { (MCT) to collect physiological data from the patient. }\end{array}$ \\
{$[39]$} & 2015 & 2016
\end{tabular}




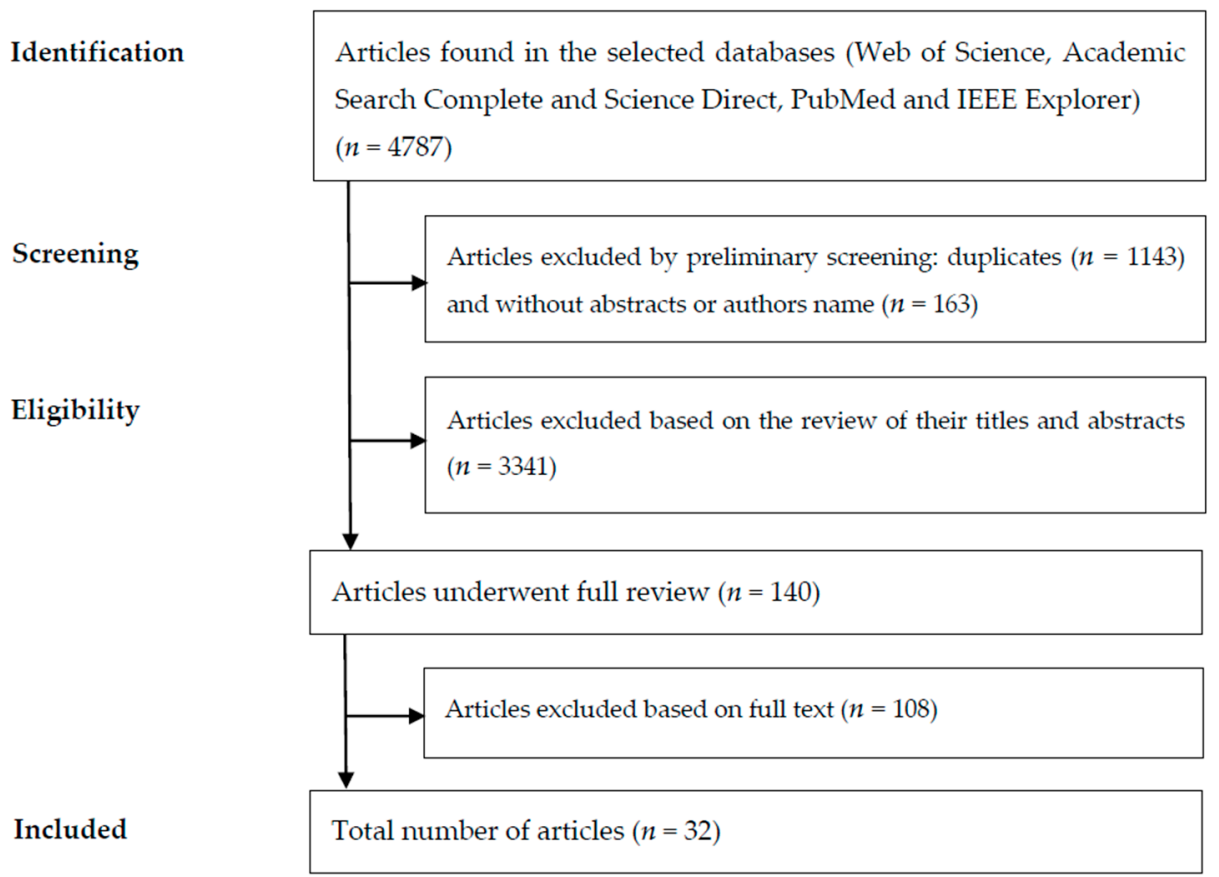

Figure 1. Preferred Reporting Items for Systematic Reviews and Meta-Analyses (PRISMA) Flowchart.

Table 2. Classification of articles by area.

\begin{tabular}{ll}
\hline \multicolumn{1}{c}{ Area } & \multicolumn{1}{c}{ Articles } \\
\hline Conceptual articles & {$[9]$} \\
Technologies & - \\
Architecture & {$[10,22,25,26]$} \\
Sensors network & {$[32]$} \\
Development methods & {$[11,12,27,29,30]$} \\
User interaction & {$[20,23,24,35,36]$} \\
Systems & - \\
Home monitoring & {$[9,13,14,28,31,33,34,37,39]$} \\
Other health care applications & {$[15-17,21]$} \\
Participation & {$[18,19]$} \\
\hline
\end{tabular}

The conceptual article [9] reports on how a combination of ambient features can be used to infer anxiety, poor sleep, depression and loneliness using linear discriminant classification and how a dynamic and holistic user-modeling could promote behavior change.

The articles classified as technologies were related to architecture, user interfaces, sensor-networks and development methods. Examples of technologies that were reported include the use of internet-based technology services to develop medical teleconsulting applications [10], the use of 3D range cameras for the detection of falls [11] or algorithms to detect a patient's emotional state by analyzing physiological signals, facial expressions and behavior [12].

The articles classified as systems reported on home monitoring services, other health care applications, and applications to promote participation. For instance, the studies of Haritou et al. [13] and Doyle et al. [14] were classified as reporting on home monitoring services. Haritou et al. [13] presents a platform that is able to monitor vital signals and to perform cognitive and behavioral assessment, as well as being able to provide early detection of symptoms and the delivery of personalized care. As well as being classified as home monitoring services, the Doyle et al. [14] study presents an integrated AAL system consisting of ambient monitoring, behavior recognition and feedback to support self-management of wellness. 
Examples of other health care applications are the studies of Corchado et al. [15], Bono-Nuez et al. [16] and Hamdan et al. [17]. Corchado et al. [15] present an intelligent environment to facilitate the management and control of geriatric residences, allowing a case-based planning with scheduling functions and mechanisms to facilitate the acquisition and management of the patient's information. The studies of Bono-Nuez et al. [16] and Hamdan et al. [17] are related to the application of AAL to measure quality of life [16] and quality of sleep [17].

Participation is the major concern of the studies of Tsardoulias et al. [18] and Dadlani et al. [19]. Tsardoulias et al. [18] report on the introduction of a socially interactive robot to physically assist and serve as a companion for older adults, while Dadlani et al. [19] report on a system designed to support the awareness of older adults living alone.

Among the 32 retrieved articles, four did not report evaluation procedures [20-23]. The remainder of the articles report various general evaluation methods and particularly the involvement of end users (e.g., older adults, health professionals or informal caregivers) to collect information in several technological development phases (Table 3): the specification of the requirements, conceptual validation (i.e., evaluating if an idea has sustainability and should be further developed) or a prototype test (i.e., an experiment conducted in a controlled environment) and pilot test (i.e., an experiment conducted in real life conditions).

Table 3. Articles that refer to user involvement.

\begin{tabular}{cc}
\hline Evaluation Type & Article (Presence of User Involvement) \\
\hline Functional requirements & {$[14,15,18,19,31,35,37,39]$} \\
Conceptual validation & {$[15,16,19,24-26,28,36]$} \\
Prototype & {$[11,12,15-19,24,25,28,30,31,35,38,40]$} \\
Pilot & {$[9,13,14,18,19,24,25,28-34]$} \\
\hline
\end{tabular}

For the functional requirements phase, Dadlini et al. [19] referred to the use of a focus group and interviews with eight caregivers and seven older adults, while Doyle et al. [14] mentioned that data collected in this phase were very rich because the authors worked very closely with the residents of a nursing home to determine their needs. In terms of conceptual validation, several methods were reported. For instance, Corchado et al. [15] and Villalba et al. [24] validated personas and scenarios through interviews with experts and final users; Augusto et al. [25] referred to the use of avatars to simulate situations and stimulate discussion with experts.

Most of the articles reported the involvement of real users in the prototype phase. Only two articles $[26,27]$ report other strategies that did not include the involvement of real users: Armentia et al. [26] reported the use of scenarios and Obukata et al. [27] reported the use of simulations.

Almost half of the articles analyzed referred to the existence of a pilot $[9,13,14,18,19,24,28-34]$, while four articles $[11,16,19,35]$ mentioned that pilots would be conducted in the future.

All but six articles $[10,20-23,36,37,39]$ reported either prototype evaluation or pilot evaluation. The duration of the pilot evaluations in particular assumed a great importance. Table 4 therefore presents the duration of the reported prototypes and pilots.

Table 4. Duration of prototypes and pilots.

\begin{tabular}{ccc}
\hline Time & Prototype & Pilot \\
\hline Not referred & 23 & 16 \\
$<1$ month & 2 & 2 \\
$>1$ month And $<3$ months & 1 & 0 \\
$>3$ months And $<3$ months & 1 & 0 \\
$>6$ months And $<3$ months & 0 & 1 \\
$>12$ months & 0 & 2 \\
\hline
\end{tabular}


None of the articles refers to a duration of the prototype evaluation of greater than three months. The duration of the pilot is also greater than the duration of the prototype on average. Nevertheless, there were pilots with a duration of less than one month: Augusto et al. [25] reported that their evaluation pilot was conducted over only 11 days and Lee et al. [29] reported that the duration of their pilot was a period of 20 days.

Only two articles reported on pilot evaluations of longer than one year. Siegel et al. [33] conducted a pilot over 18 months and used several instruments to measure health-related outcomes, while Doyle et al. [14] developed an integrated home-based AAL system for adults consisting of ambient monitoring, behavior recognition and feedback to support the self-management of wellness, home security and home energy. This system was installed in 16 smart homes in Ireland in which older people have lived since 2010. Data from 2240 sensors were collected. Sensors were tested periodically and information about the performance of the system tested and health and wellbeing assessments were gathered through validated instruments.

A great variety of assessment instruments were reported. Table 5 presents the methods and instruments that were used during different development phases (i.e., the specification of requirements, conceptual validation, prototype test and pilot test). When analyzing the assessment of health-related outcomes, the following instruments were identified:

- Activities of Daily Living (ADL) instruments: instruments that measure the skills of a person in performing basic activities, such as activities related to independent living (i.e., self-care, dressing, eating or mobility) [41].

- Instrumental Activities of Daily Living (IADL) instruments: instruments that measure the skills required for a person to live in a community, such as shopping, managing finances, housekeeping, and meal preparation [41].

- World Health Organization Quality of Life for Older Persons (WHOQOL-OLD): an instrument designed to measure the quality of life of older adults [42].

- Patient Health Questionnaire-9 (PHQ-9): a self-administered diagnostic instrument to assess depression [43].

- 10-min walking test: a test to assess disability by measuring a person's performance [44].

- Time Up and Go: a test to measure the time it takes a person to stand up from an armchair, walk a distance of three meters, turn, walk back to the chair, and sit down [45].

- Inverted L exercise: a physical exercise where the body stays in the position of an L.

- Mini-Mental State Examination (MMSE): a screening instrument for the detection of dementia [46].

- World Health Organization Quality of Life-Brief (WHOQOL-BREF): abbreviated version of the World Health Organization Quality of Life-100 (WHOQOL-100), to assess quality of life [47].

- EuroQol five dimensions questionnaire (EQ-5D): a generic five-part questionnaire with a visual analogue self-rating scale [48] to measure health status.

- Health-threatening events in the past: a questionnaire related to house conditions, the frequency of falls, chronic diseases, previous health-threatening events, level of social support and medicine intake [33].

- Support for limitations: a questionnaire related to physical limitations during ADL or the need of support for ADL activities or for memory tasks [33].

- Center for Epidemiologic Studies Depression Scale (CES-D): a self-report instrument designed to measure depressive symptomatology [49].

- Hospital Anxiety and Depression Scale (HADS): a self-report instrument designed to detect states of depression and anxiety in a hospital or medical outpatient clinic setting [50].

- Montreal Cognitive Assessment (MOCA): an instrument designed to assess cognitive impairment [51].

- 36-Item Short Form Survey (SF-36): a 36-item self-report instrument designed to assess overall health conditions, including health-related quality of life [52]. 
- De Jong scale: an instrument designed to assess emotional and social loneliness [53].

- Pittsburgh Sleep Quality Index (PSQI): a self-rated questionnaire to assess sleep quality and disturbances [54].

Table 5. Evaluation methods and instruments.

\begin{tabular}{|c|c|c|}
\hline Phase & Article & Evaluation Techniques \\
\hline \multirow{3}{*}{ Functional requirements } & [37] & $\begin{array}{l}\text { Instruments to measure ADL and IADL, WHOQOL-OLD } \\
\text { and questionnaires }\end{array}$ \\
\hline & [39] & Questionnaires \\
\hline & [18] & Focus group \\
\hline Conceptual validation & [28] & Brainstorming \\
\hline \multirow{7}{*}{ Prototype } & [19] & Interviews and questionnaires \\
\hline & [17] & Questionnaires \\
\hline & [25] & Personas and scenarios, focus group and questionnaires \\
\hline & [26] & Scenarios \\
\hline & [12] & PHQ-9 \\
\hline & [18] & $\begin{array}{l}\text { Usability tests, 10-min walking test, TUG and inverted L } \\
\text { exercise }\end{array}$ \\
\hline & [27] & Simulation \\
\hline \multirow{5}{*}{ Pilot } & [19] & $\begin{array}{l}\text { Connectedness questionnaires, usability tests (adapted } \\
\text { questionnaire), expectation questionnaires }\end{array}$ \\
\hline & [28] & Usability tests (heuristic evaluation) \\
\hline & [33] & $\begin{array}{l}\text { MMSE, WHOQOL-BREF, WHOQOL-OLD, EQ5D, focus } \\
\text { groups, TAEG, usability tests, interviews, perceived system } \\
\text { satisfaction, frequency of usage (technical analysis), } \\
\text { sociodemographic parameters, health threatening event in } \\
\text { the past and support for limitations }\end{array}$ \\
\hline & [14] & $\begin{array}{l}\text { Wellbeing questionnaire, interviews, CES-D, HADS, MOCA, } \\
\text { SF-36, DE Jong scale and PSQI }\end{array}$ \\
\hline & [34] & $\begin{array}{l}\text { Wellbeing questionnaire, interviews, CES-D, HADS, MOCA, } \\
\text { SF-36, DE Jong scale and PSQI }\end{array}$ \\
\hline
\end{tabular}

Of all articles, ten referred the use of different instruments, of which six $[12,14,18,33,34,37]$ specified which instruments were used to measure health-related outcomes: depression (i.e., PHQ-9 [12] and CES-D [14,34]); mental conditions (i.e., MMSE [33] and MOCA [14,34]); general health status (i.e., EQ5D [33] and SF-36 [14,34]); ADL and IADL [37]; physical condition (i.e., TUG [18], Inverted L [18] and 10-min walking test [18]); emotional and social loneliness (i.e., DE Jong scale [14,34]); hospital anxiety and depression (i.e., HADS [14,34]); sleep quality (i.e., PSQI [14,34]); and quality of life (i.e., WHOQOL-BREF [33] and WHOQOL-OLD [33,37]). Some articles referred to the use of instruments but did not specify which instruments were used $[17,25,39]$. Three articles referred to adaptations of existing instruments [19,34] or the development of new ones [37] but did not refer to the validation process. Finally, one article [14] reported on the integration of validated instruments to measure health-related outcomes together with mechanisms for ambient monitoring and behaviour recognition to support the self-management of wellness.

\section{Discussion}

This systematic review aimed to identify how the impact of state-of-the-art AAL solutions is being assessed in terms of its health-related outcomes. Considering the retrieved articles, there is an 
equilibrium between studies focusing on the development of new technologies and studies focusing on the development and evaluation of user-centered services. This conclusion is slightly different from that of Queirós et al. [3], who reported a concern in explaining the development of technological solutions rather than the development of services that could satisfy the real needs of older adults. Nevertheless, it appears that the main concern is still the development rather than evaluation of the impact of AAL solutions on the health conditions of older adults.

Concerning the first research question- "what AAL solutions being reported in the literature to improve health conditions were evaluated in terms of health-related outcomes?" - the results show that a considerable number of articles classified as systems report on home monitoring solutions. Within this group, some articles report on the development of platforms that are able to gather different types of data to infer patterns, emotions and health conditions [13,14,28,34]. A smaller number of articles refer to specific health care applications: Bono-Nuez et al. [16] developed a tool to evaluate the quality of life of older adults and disabled people, Hamdan et al. [17] proposed a biofeedback system to measure the quantity and quality of sleep, while Fratu et al. [21] developed a supervising and monitoring system for chronic obstructive pulmonary disease and mild dementia patients. There is a more limited number of articles that refer to participation; these are related to the use of an interactive robot to assist with physical tasks and to serve as companion to older people [18] and an awareness system to support independent living and to give peace of mind to relatives [19].

The results also show concerns related to the involvement of users in all of the developmental phases, which is an essential requirement when developing AAL solutions [55].

Concerning the second research question-"does the literature present evidence of the impact of AAL solutions in terms of health-related outcomes?"- the results show that there are several articles referring to terms such as quality of life, well-being, health improvement, health or the promotion of health in the title or the abstract; however, a lower number of articles mention these terms in all sections or explain and describe the work related to these terms that has been done. It appears that these concepts are referred to in the initial sections or in the conclusion because they are important concepts related to AAL, or as a marketing strategy, but that they are not considered in the description of developments or in the presentation of results.

Since the retrieved articles are related to AAL applications in the healthcare domain, health-related outcomes including quality of life should be considered when evaluating these solutions. However, this review shows that many articles do not provide sufficient information on the evaluation methods and outcomes, particularly in terms of the impact of these solutions in the daily lives of their users. Out of 32 articles, only 7 refer to the application of instruments to measure health-related outcomes (Table 5). This was also referred to in the study of Siegel and Dorner [56].

Furthermore, to understand the impact of the AAL solutions being developed, it is necessary to evaluate their use in real contexts and over long periods. For instance, it is important to understand if the results of the evaluation of a specific solution are influenced by the fact that the use of technology is new to the involved users or if the conditions in the environment are adequate for the use of the solution being evaluated. As presented in Table 4, none of the articles report a prototype evaluation period of greater than three months and only one pilot is referred to as a clinical trial [33]. Furthermore, the authors of four articles $[11,16,35,38]$ did not implement a pilot and rather reported that they were planning to implement it in the future. This is in line with the eHealth Action Plan 2012-2020 [57], which refers to the limited large-scale evidence of the cost-effectiveness of eHealth tools and services as one of the barriers to the deployment of eHealth.

Concerning the third research question-" what methods are being used to measure the impact of AAL solutions in terms of health-related outcomes?"-Table 5 presents the evaluation methods and instruments reported by the included articles. Despite the fact that different phases are mentioned in several articles, the results seem to show that there is a concern about using instruments related to the user and his/her health condition in addition to technological assessment instruments (e.g., usability evaluation). Several instruments to measure health-related outcomes are referred to in prototype 
and pilot phases. Stardoulias et al. [18] used instruments such as the TUG-an instrument to assess a person's functional mobility-or the 10-minute walking test-a measure of performance-in the prototype phase. Fernandez-Caballero et al. [12] used the PHQ-9-a clinical instrument to assess depression-in the prototype phase. Concerning the evaluation of the pilot, Bono-Nuez et al. [33] refer to the use of several instruments designed to measure health-related outcomes, such as MMSE, WHOQOL-BREF, WHOQOL-OLD and EQ5D-VAS. Doyle et al. [14] and Kealy et al. [34] also refer to instruments designed to measure health-related outcomes. These results suggest that there is an increasing interest in the evaluation of the impact of AAL solutions in terms of their health-related outcomes.

The results of this systematic review show that, while there are a large number of AAL solutions during the period being analyzed, as demonstrated by the initial number of articles collected (4787 articles), the number of retrieved articles for the purpose of this review is comparatively low (32). The results seem to demonstrate that AAL developers are most concerned with systems and the involvement of real users in an attempt to cater to the needs of older adults. There also seems to be an interest in evaluating outcomes and comparing them with measurements of health-related outcomes. Nevertheless, many of the articles do not provide sufficient information on the assessment procedures to evaluate the impact of the AAL solutions in terms of their health-related outcomes.

Despite a high level of technological innovation and implementation, these results show that a considerable number of AAL developments aim for the design, development and evaluation of prototypes (i.e., proof-of-concept). In turn, when assessing the impact on the users, particularly in terms of health-related outcomes, there is a need for evidence with statistical significance to show that these new developments can make a difference and are cost-effective [58].

Collecting this kind of evidence is only possible with large interventional field trials that require multidisciplinary collaboration and demand considerable resources to integrate new applications with daily care-delivery running over long periods and used by thousands of users including patients and care-providers [59]. These trials present demanding methodological, organizational and ethical challenges, since the involvement of older adults, some of them with disabilities, in a laboratory context is not straightforward; it is, however, even more difficult to monitor and interact with them in their home environments. The analysis of the duration of the experiments with real users (Table 4) makes evident the difficulty in conducting interventional trials that are able to provide the required significant evidence, as only two articles reported pilot evaluation durations above one year.

\section{Conclusions}

The aim of the active ageing paradigm is that everyone might live a healthy, autonomous, high-quality and independent life. Ambient Assisted Living (AAL) might contribute to the improvement of the health conditions of older adults through technological solutions. This article reviews how the impact of state-of-art AAL technologies, products and services is being measured in terms of their health-related outcomes.

The limitations of this work are related to the dependency on its keywords and the databases selected. Despite these limitations, the authors believe that the systematically-collected evidence contributes to the understanding of trends in the development of AAL technologies, products and services.

Acknowledgments: This work was partially supported by COMPETE-Programa Operacional Competitividade e Internacionalização (COMPETE 2020), Sistema de Incentivos à Investigação e Desenvolvimento Tecnológico (SI I\&DT), under the project Social Cooperation for Integrated Assisted Living (SOCIAL).

Author Contributions: A.Q. and N.P.R. conceived and designed the systematic review; A.Q., A.D. and A.G.S. performed the literature review and analyzed the data; A.Q. and N.P.R. wrote the article. All the authors review the article and approved the final version.

Conflicts of Interest: The authors declare no conflict of interest. 


\section{References}

1. Kinsella, K.G.; Phillips, D.R. Global Aging: The Challenge of Success; Population Reference Bureau: Washington, DC, USA, 2005; Volume 60.

2. World Health Organization (WHO). Global Strategy and Action Plan on Ageing and Health; WHO: Geneva, Switzerland, 2016.

3. Queirós, A.; Silva, A.G.; Alvarelhão, J.; Teixeira, A.; Da Rocha, N.P. Ambient Assisted Living Technologies, Systems and Services: A Systematic Literature Review. In Proceedings of the 2nd International Living Usability Lab Workshop on AAL Latest Solutions, Trends and Applications, Vilamoura, Algarve, Portugal, 1-4 February 2012; pp. 14-26.

4. Glass, T.A.; McAtee, M.J. Behavioral science at the crossroads in public health: Extending horizons, envisioning the future. Soc. Sci. Med. 2006, 62, 1650-1671. [CrossRef] [PubMed]

5. Fayers, P.M.; Machin, D. Quality of Life: The Assessment, Analysis and Interpretation of Patient-Reported Outcomes; John Wiley \& Sons: Hoboken, NJ, USA, 2013.

6. Porter, M.E.; Larsson, S.; Lee, T.H. Standardizing patient outcomes measurement. N. Engl. J. Med. 2016, 374, 504-506. [CrossRef] [PubMed]

7. Moher, D.; Liberati, A.; Tetzlaff, J.; Altman, D.G.; Group, P. Preferred reporting items for systematic reviews and meta-analyses: The PRISMA statement. PLoS Med. 2009, 6, e1000097. [CrossRef] [PubMed]

8. European Economic and Social Comitte. Opinion of the European Economic and Social Committee on the Proposal for a Decision of the European Parliament and of the Council on the Participation by the Community in a Research and Development Programme Aimed at Enhancing the Quality of Life of Older People through the Use of new Information and Communication Technologies (ICT), Undertaken by Several Member States. Official J. Eur. Union 2008, 51, C224/02.

9. Lindgren, H.; Baskar, J.; Guerrero, E.; Nieves, J.C.; Nilsson, I.; Yan, C. Computer-Supported Assessment for Tailoring Assistive Technology. In Proceedings of the 6th International Conference on Digital Health Conference, Montréal, QC, Canada, 11-13 April 2016; pp. 1-10.

10. Moreno, P.A.; Hernando, M.E.; Gómez, E.J.; Del Egido, R.P.; Matilla, Ó.B.; de Poorter, A.; Ortiz, A.H.; Vidal, F.G. Teleconsulting: A Medical Application Based on IP Multimedia Subsystem Technology for Ambient Assisted Living. In Proceedings of the 2nd International Symposium on Applied Sciences in Biomedical and Communication Technologies, Bratislava, Slovakia, 24-27 November 2009; pp. 1-6.

11. Leone, A.; Diraco, G.; Siciliano, P. Detecting falls with $3 \mathrm{D}$ range camera in ambient assisted living applications: A preliminary study. Med. Eng. Phys. 2011, 33, 770-781. [CrossRef] [PubMed]

12. Fernández-Caballero, A.; Martínez-Rodrigo, A.; Pastor, J.M.; Castillo, J.C.; Lozano-Monasor, E.; López, M.T.; Zangróniz, R.; Latorre, J.M.; Fernández-Sotos, A. Smart environment architecture for emotion detection and regulation. J. Biomed. Inf. 2016, 64, 55-73. [CrossRef] [PubMed]

13. Haritou, M.; Glickman, Y.; Androulidakis, A.; Xefteris, S.; Anastasiou, A.; Baboshin, A.; Cuno, S.; Koutsouris, D. A technology platform for a novel home care delivery service to patients with dementia. J. Med. Imaging Health Inf. 2012, 2, 49-55. [CrossRef]

14. Doyle, J.; Kealy, A.; Loane, J.; Walsh, L.; O'mullane, B.; Flynn, C.; Macfarlane, A.; Bortz, B.; Knapp, R.B.; Bond, R. An integrated home-based self-management system to support the wellbeing of older adults. J. Ambient Intell. Smart Environ. 2014, 6, 359-383.

15. Corchado, J.M.; Bajo, J.; Abraham, A. GerAmi: Improving healthcare delivery in geriatric residences. IEEE Intell. Syst. 2008, 23. [CrossRef]

16. Bono-Nuez, A.; Martín-del-Brío, B.; Blasco-Marín, R.; Casas-Nebra, R.; Roy-Yarza, A. Quality of life evaluation of elderly and disabled people by using self-organizing maps. Distrib. Comput. Artif. Intell. Bioinf. Soft Comput. Ambient Assist. Living 2009, 906-913. [CrossRef]

17. Hamdan, S.; Al Osman, H.; Eid, M.; El Saddik, A. A Biofeedback System for Sleep Management. In Proceedings of the 2012 IEEE International Symposium on Robotic and Sensors Environments (ROSE), Magdeburg, Germany, 16-18 November 2012; pp. 133-137.

18. Tsardoulias, E.G.; Kintsakis, A.M.; Panayiotou, K.; Thallas, A.G.; Reppou, S.E.; Karagiannis, G.G.; Iturburu, M.; Arampatzis, S.; Zielinski, C.; Prunet, V. Towards an integrated robotics architecture for social inclusion-The RAPP paradigm. Cogn. Syst. Res. 2017, 43, 157-173. [CrossRef] 
19. Dadlani, P.; Markopoulos, P.; Sinitsyn, A.; Aarts, E. Supporting peace of mind and independent living with the Aurama awareness system. J. Ambient Intell. Smart Environ. 2011, 3, 37-50.

20. Doukas, C.; Metsis, V.; Becker, E.; Le, Z.; Makedon, F.; Maglogiannis, I. Digital cities of the future: Extending@ home assistive technologies for the elderly and the disabled. Telemat. Inf. 2011, 28, 176-190. [CrossRef]

21. Fratu, O.; Pena, C.; Craciunescu, R.; Halunga, S. Fog Computing System for Monitoring Mild Dementia and COPD Patients-Romanian Case Study. In Proceedings of the 2015 12th International Conference on Telecommunication in Modern Satellite, Cable and Broadcasting Services (TELSIKS), Nis, Serbia, 14-17 October 2015; pp. 123-128.

22. Leone, A.; Diraco, G.; Siciliano, P. Context-aware AAL services through a 3D sensor-based platform. J. Sens. 2013, 2013, 792978. [CrossRef]

23. Zejda, D. Deep Design for Ambient Intelligence: Toward Acceptable Appliances for Higher quAlity of Life of the Elderly. In Proceedings of the 2010 Sixth International Conference on Intelligent Environments (IE), Kuala Lumpur, Malaysia, 19-21 July 2010; pp. 277-282.

24. Villalba, E.; Salvi, D.; Peinado, I.; Ottaviano, M.; Arredondo, M.T. Validation Results of the User Interaction in a Heart Failure Management System. In Proceedings of the 2009 eTELEMED'09 International Conference on eHealth, Telemedicine, and Social Medicine, Cancun, Mexico, 1-7 February 2009; pp. 81-86.

25. Augusto, J.; Mulvenna, M.; Zheng, H.; Wang, H.; Martin, S.; McCullagh, P.; Wallace, J. Night optimised care technology for users needing assisted lifestyles. Behav. Inf. Technol. 2014, 33, 1261-1277. [CrossRef]

26. Armentia, A.; Gangoiti, U.; Priego, R.; Estevez, E.; Marcos, M. A Multi-Agent Based Approach to Support Adaptability in Home Care Applications. IFAC-PapersOnLine 2015, 48, 1-6. [CrossRef]

27. Obukata, R.; Oda, T.; Barolli, L. Design of an Ambient Intelligence Testbed for Improving Quality of Life. In Proceedings of the 2016 30th International Conference on Advanced Information Networking and Applications Workshops (WAINA), Crans-Montana, Switzerland, 23-25 March 2016; pp. 714-719.

28. Bono-Nuez, A.; Blasco, R.; Casas, R.; Martín-del-Brío, B. Ambient intelligence for quality of life assessment. J. Ambient Intell. Smart Environ. 2014, 6, 57-70.

29. Lee, C.S.; Wang, M.H.; Acampora, G.; Hsu, C.Y.; Hagras, H. Diet assessment based on type-2 fuzzy ontology and fuzzy markup language. Int. J. Intell. Syst. 2010, 25, 1187-1216. [CrossRef]

30. Mowafey, S.; Gardner, S. Towards Ambient Intelligence in Assisted Living: The Creation of an Intelligent Home Care. In Proceedings of the Science and Information Conference (SAI), London, UK, 7-9 October 2013; pp. 51-60.

31. Rocha, A.; Martins, A.; Freire, J.C.; Boulos, M.N.K.; Vicente, M.E.; Feld, R.; van de Ven, P.; Nelson, J.; Bourke, A.; ÓLaighin, G. Innovations in health care services: The CAALYX system. Int. J. Med. Inf. 2013, 82, e307-e320. [CrossRef] [PubMed]

32. Rodríguez, S.; De Paz, J.F.; Villarrubia, G.; Zato, C.; Bajo, J.; Corchado, J.M. Multi-agent information fusion system to manage data from a WSN in a residential home. Inf. Fusion 2015, 23, 43-57. [CrossRef]

33. Siegel, C.; Prazak-Aram, B.; Kropf, J.; Kundi, M.; Dorner, T. Evaluation of a modular scalable system for silver-ager located in assisted living homes in Austria-Study protocol of the ModuLAAr ambient assisted living project. BMC Public Health 2014, 14, 736. [CrossRef] [PubMed]

34. Walsh, L.; Kealy, A.; Loane, J.; Doyle, J.; Bond, R. Inferring Health Metrics from Ambient Smart Home Data. In Proceedings of the 2014 IEEE International Conference on Bioinformatics and Biomedicine (BIBM), Belfast, UK, 2-5 November 2014; pp. 27-32.

35. Sixsmith, A.; Meuller, S.; Lull, F.; Klein, M.; Bierhoff, I.; Delaney, S.; Savage, R. SOPRANO—An Ambient Assisted Living System for Supporting Older People at Home. In Proceedings of the International Conference on Smart Homes and Health Telematics, Tours, France, 1-3 July 2009; pp. 233-236.

36. Kaklauskas, A.; Zavadskas, E.K.; Naimavicienė, J.; Krutinis, M.; Plakys, V.; Venskus, D. Model for a complex analysis of intelligent built environment. Autom. Constr. 2010, 19, 326-340. [CrossRef]

37. Aquilano, M.; Cavallo, F.; Bonaccorsi, M.; Esposito, R.; Rovini, E.; Filippi, M.; Esposito, D.; Dario, P.; Carrozza, M.C. Ambient Assisted Living and Ageing: Preliminary Results of RITA Project. In Proceedings of the 2012 Annual International Conference of the IEEE Engineering in Medicine and Biology Society (EMBC), San Diego, CA, USA, 28 August-1 September 2012; pp. 5823-5826.

38. Cavallo, F.; Limosani, R.; Manzi, A.; Bonaccorsi, M.; Esposito, R.; Di Rocco, M.; Pecora, F.; Teti, G.; Saffiotti, A.; Dario, P. Development of a socially believable multi-robot solution from town to home. Cogn. Comput. 2014, 6, 954-967. [CrossRef] 
39. Wessig, K. Self Evolutory Systems and the Kinetics of Aging. In Proceedings of the 2015 8th International Conference on Human System Interactions (HSI), Warsaw, Poland, 25-27 June 2015; pp. 11-14.

40. Pereira, F.; Carvalho, V.; Soares, F.; Machado, J.; Bezerra, K.; Silva, R.; Matos, D. Development of a Medical Care Terminal for Efficient Monitoring of Bedridden Subjects. J. Eng. 2016, 2016, 3591059. [CrossRef]

41. Spector, W.D.; Fleishman, J.A. Combining activities of daily living with instrumental activities of daily living to measure functional disability. J. Gerontol. Ser. B 1998, 53, S46-S57. [CrossRef]

42. Power, M.; Quinn, K.; Schmidt, S. Development of the WHOQOL-old module. Qual. Life Res. 2005, 14, 2197-2214. [CrossRef] [PubMed]

43. Kroenke, K.; Spitzer, R.L.; Williams, J.B. The Phq-9. J. Gen. Int. Med. 2001, 16, 606-613. [CrossRef]

44. Singh, S.J.; Morgan, M.; Scott, S.; Walters, D.; Hardman, A.E. Development of a shuttle walking test of disability in patients with chronic airways obstruction. Thorax 1992, 47, 1019-1024. [CrossRef] [PubMed]

45. Podsiadlo, D.; Richardson, S. The timed "Up \& Go": A test of basic functional mobility for frail elderly persons. J. Am. Gerizatr. Soc. 1991, 39, 142-148.

46. Lourenço, R.A.; Veras, R.P. Mini-Mental State Examination: Psychometric characteristics in elderly outpatients. Revista de Saúde Pública 2006, 40, 712-719. [CrossRef] [PubMed]

47. Group, W. Development of the World Health Organization WHOQOL-BREF quality of life assessment. Psychol. Med. 1998, 28, 551-558.

48. Group, T.E. EuroQol-a new facility for the measurement of health-related quality of life. Health Policy 1990, 16, 199-208.

49. Radloff, L.S. The CES-D scale: A self-report depression scale for research in the general population. Appl. Psychol. Meas. 1977, 1, 385-401. [CrossRef]

50. Zigmond, A.S.; Snaith, R.P. The hospital anxiety and depression scale. Acta Psychiatr. Scand. 1983, 67, 361-370. [CrossRef] [PubMed]

51. Nasreddine, Z.S.; Phillips, N.A.; Bédirian, V.; Charbonneau, S.; Whitehead, V.; Collin, I.; Cummings, J.L.; Chertkow, H. The Montreal Cognitive Assessment, MoCA: A brief screening tool for mild cognitive impairment. J. Am. Geriatr. Soc. 2005, 53, 695-699. [CrossRef] [PubMed]

52. Ware, J.E., Jr.; Sherbourne, C.D. The MOS 36-item short-form health survey (SF-36): I. Conceptual framework and item selection. Med. Care 1992, 30, 473-483. [CrossRef] [PubMed]

53. De Jong-Gierveld, J.; Kamphuls, F. The development of a Rasch-type loneliness scale. Appl. Psychol. Meas. 1985, 9, 289-299. [CrossRef]

54. Buysse, D.J.; Reynolds, C.F.; Monk, T.H.; Berman, S.R.; Kupfer, D.J. The Pittsburgh Sleep Quality Index: A new instrument for psychiatric practice and research. Psychiatr. Res. 1989, 28, 193-213. [CrossRef]

55. Martins, A.I.; Queirós, A.; Silva, A.G.; Rocha, N.P. Usability Evaluation of Ambient Assisted Living Systems Using a Multi-Method Approach. In Proceedings of the 7th International Conference on Software Development and Technologies for Enhancing Accessibility and Fighting Info-exclusion, Vila Real, Portugal, 1-3 December 2016; pp. 261-268.

56. Siegel, C.; Dorner, T.E. Information technologies for active and assisted living-Influences to the quality of life of an ageing society. Int. J. Med. Inf. 2017, 100, 32-45. [CrossRef] [PubMed]

57. European Comission. eHealth Action Plan 2012-2020-Innovative Healthcare for the 21st Century; European Comission: Brussels, Belgium, 2012.

58. Korhonen, I.; Barddram, J. Guest editorial introduction to the special section on pervasive healthcare. IEEE Trans. Inf. Technol. Biomed. 2004, 8, 229-234. [CrossRef] [PubMed]

59. Rashidi, P.; Mihailidis, A. A Survey on Ambient-Assisted Living Tools for Older Adults. IEEE J. Biomed. Health Inf. 2013, 17, 579-590. [CrossRef]

(C) 2017 by the authors. Licensee MDPI, Basel, Switzerland. This article is an open access article distributed under the terms and conditions of the Creative Commons Attribution (CC BY) license (http:/ / creativecommons.org/licenses/by/4.0/). 